\title{
Approximating fixed points for nonself mappings in CAT(0) spaces
}

\author{
Abdolrahman Razani and Saeed Shabani
}

* Correspondence: $s$.

shabani@srbiau.ac.ir

Department of Mathematics,

Science and Research Branch,

Islamic Azad University, Tehran, Iran

\begin{abstract}
Suppose $K$ is a nonempty closed convex subset of a complete CAT(0) space $X$ with the nearest point projection $P$ from $X$ onto $K$. Let $T: K \rightarrow X$ be a nonself mapping, satisfying Condition $(E)$ with $F(T):=\{x \in K: T x=x\} \neq \varnothing$. Suppose $\left\{x_{n}\right\}$ is generated iteratively by $x_{1} \in K, x_{n+1}=P\left(\left(1-\alpha_{n}\right) x_{n} \oplus \alpha_{n} T P\left[\left(1-\beta_{n}\right) x_{n} \oplus \beta_{n} T x_{n}\right]\right), n \geq 1$, where $\left\{\alpha_{n}\right\}$ and $\left\{\beta_{n}\right\}$ are real sequences in $\left[\varepsilon_{1} 1-\varepsilon\right]$ for some $\varepsilon \in(0,1)$. Then, $\left\{x_{n}\right\}$ $\triangle$-converges to some point $x^{\star}$ in $F(T)$. This extends a result of Laowang and Panyanak [Fixed Point Theory Appl. 367274, 11 (2010)] for nonself mappings satisfying Condition (E).
\end{abstract}

Keywords: CAT(O) spaces, fixed point, condition (E), nonself mappings

\section{Introduction}

In 2010, Laowang and Panyanak [1] studied an iterative scheme and proved the following result: let $K$ be a nonempty closed convex subset of a complete $\operatorname{CAT}(0)$ space $X$, (the initials of term "CAT" are in honor of E. Cartan, A.D. Alexanderov and V.A. Toponogov) with the nearest point projection $P$ from $X$ onto $K$. Let $T: K \rightarrow X$ be a nonexpansive nonself mapping with nonempty fixed point set. If $\left\{x_{n}\right\}$ is generated iteratively by

$$
x_{1} \in K, \quad x_{n+1}=P\left(\left(1-\alpha_{n}\right) x_{n} \oplus \alpha_{n} T P\left[\left(1-\beta_{n}\right) x_{n} \oplus \beta_{n} T x_{n}\right]\right),
$$

where $\left\{\alpha_{n}\right\}$ and $\left\{\beta_{n}\right\}$ are real sequences in $[\varepsilon, 1-\varepsilon]$ for some $\varepsilon \in(0,1)$, then $\left\{x_{n}\right\}$ is $\Delta$-convergent to a fixed point of $T$. In this article, this result is extended for nonself mappings satisfying Condition $(E)$.

Let $K$ be a nonempty subset of a $\operatorname{CAT}(0)$ space $X$ and $T: K \rightarrow X$ be a mapping. A point $x \in K$ is called a fixed point of $T$, if $x=T x$. We shall denote the fixed point set of $T$ by $F(T)$. Moreover, $T$ is called nonexpansive if for each $x, y \in K, d(T x, T y) \leq d(x, y)$.

In 2011, Falset et al. [2] introduced Condition $(E)$ as follows:

Definition 1.1. Let $K$ be a bounded closed convex subset of a complete CAT $(0)$ space $X$. A mapping $T: K \rightarrow X$ is called to satisfy Condition $\left(E_{\mu}\right)$ on $C$, if there exists $\mu \geq 1$ such that

$$
\mathrm{d}(x, T y) \leq \mu \mathrm{d}(T x, x)+\mathrm{d}(x, y)
$$

holds, for all $x, y \in K$. It is called, $T$ satisfies Condition $(E)$ on $C$ whenever $T$ satisfies $\left(E_{\mu}\right)$ for some $\mu \geq 1$. 
Proposition 1.2 [2]. Every nonexpansive mapping satisfies Condition (E), but the inverse is not true.

Now, we need some fact about CAT(0) spaces as follows:

Let $(X, d)$ be a metric space. A geodesic path joining $x \in X$ to $y \in X$ (or, more briefly, a geodesic from $x$ to $y$ ) is a map $c$ from a closed interval $[0, l] \subset R$ to $X$ such that $c(0)=x, c$ $(l)=y$ and $\mathrm{d}\left(c(t), c\left(t^{\prime}\right)\right)=\left\|t-t^{\prime}\right\|$ for all $t, t^{\prime} \in[0, l]$. In particular, $c$ is an isometry and $\mathrm{d}(x$, $y)=l$. The image $\alpha$ of $c$ is called a geodesic (or metric) segment joining $x$ and $y$. When it is unique, this geodesic is denoted by $[x, y]$. The space $(X, d)$ is said to be a geodesic space, if every two points of $X$ are joined by a geodesic, and $X$ is said to be uniquely geodesic if there is exactly one geodesic joining $x$ to $y$, for each $x, y \in X$. A subset $Y \subset X$ is said to be convex if $Y$ includes every geodesic segment joining any two of its points. A geodesic triangle $\Delta\left(x_{1}, x_{2}, x_{3}\right)$ in a geodesic metric space $(X, d)$ consists of three points in $X$ (the vertices of $\Delta$ ) and a geodesic segment between each pair of vertices (the edges of $\Delta$ ). A comparison triangle for geodesic triangle $\Delta\left(x_{1}, x_{2}, x_{3}\right)$ in $(X, d)$ is a triangle $\bar{\Delta}\left(x_{1}, x_{2}, x_{3}\right):=\Delta\left(\bar{x}_{1}, \bar{x}_{2}, \bar{x}_{3}\right)$ in the Euclidean plane $E^{2}$ such that $d_{E^{2}}\left(\bar{x}_{i}, \bar{x}_{j}\right)=d\left(x_{i}, x_{j}\right)$ for $i, j \in\{1,2,3\}$. A geodesic metric space is said to be a CAT(0) space [3], if all geodesic triangles of appropriate size satisfy the following comparison axiom. Let $\Delta$ be a geodesic triangle in $X$ and $\bar{\Delta}$ be a comparison triangle for $\Delta$. Then $\Delta$ is said to satisfy the $\operatorname{CAT}(0)$ inequality if for all $x, y \in \Delta$ and all comparison points $\bar{x}, \bar{y} \in \bar{\Delta}$,

$$
\mathrm{d}(x, y) \leq \mathrm{d}_{E^{2}}(\bar{x}, \bar{y})
$$

If $x, y_{1}, y_{2}$ are points in a CAT(0) space and $y_{0}$ is the midpoint of the segment $\left[y_{1}\right.$, $y_{2}$ ], then the $\operatorname{CAT}(0)$ inequality implies

$$
\mathrm{d}\left(x, y_{0}\right)^{2} \leq \frac{1}{2} \mathrm{~d}\left(x, y_{1}\right)^{2}+\frac{1}{2} \mathrm{~d}\left(x, y_{2}\right)^{2}-\frac{1}{4} \mathrm{~d}\left(y_{1}, y_{2}\right)^{2} .
$$

In fact, a geodesic space is a $\mathrm{CAT}(0)$ space if and only if it satisfies the $(\mathrm{CN})$ inequality (Courbure negative) [[3], p. 163].

Lemma 1.3. Let $(X, d)$ be a $C A T(0)$ space.

1. [[3], Proposition 2.4] Let $K$ be a convex subset of $X$ which is complete in the induced metric. Then for every $x \in X$, there exists a unique point $P(x) \in K$ such that $d(x, P(x))=\inf \{d(x, y): y \in K\}$. Moreover, the map $x \rightarrow P(x)$ is a nonexpansive retract from $X$ onto $K$.

2. [[4], Lemma 2.1] For $x, y \in X$ and $t \in[0,1]$, there exists a unique point $z \in[x$, $y$ ] such that

$$
\mathrm{d}(x, z)=t \mathrm{~d}(x, y), \quad \mathrm{d}(y, z)=(1-t) \mathrm{d}(x, y)
$$

one uses the notation $(1-t) x \oplus$ ty for the unique point $z$.

3. [[4], Lemma 2.4] For $x, y, z \in X$ and $t \in[0,1]$, one has

$$
\mathrm{d}((1-t) x \oplus t y, z) \leq(1-t) \mathrm{d}(x, z)+t \mathrm{~d}(y, z) .
$$

[[4], Lemma 2.5] For $x, y, z \in X$ and $t \in[0,1]$, one has

$$
d((1-t) x \oplus t y, z)^{2} \leq(1-t) \mathrm{d}(x, z)^{2}+t \mathrm{~d}(y, z)^{2}-t(1-t) \mathrm{d}(x, y)^{2} .
$$


Let $\left\{x_{n}\right\}$ be a bounded sequence in a $\operatorname{CAT}(0)$ space $X$. For $x \in X$, we set

$$
r\left(x,\left\{x_{n}\right\}\right)=\limsup _{n \rightarrow \infty} \mathrm{d}\left(x, x_{n}\right) .
$$

The asymptotic radius

$$
r\left(\left\{x_{n}\right\}\right)=\inf \left\{r\left(x,\left\{x_{n}\right\}\right): x \in X\right\},
$$

and the asymptotic center $A\left(\left\{x_{n}\right\}\right)$ of $\left\{x_{n}\right\}$ is the set

$$
A\left(\left\{x_{n}\right\}\right)=\left\{x \in X: r\left(x,\left\{x_{n}\right\}\right)=r\left(\left\{x_{n}\right\}\right)\right\} .
$$

It is known [[5], Proposition 7], in a CAT(0) space $X, A\left(\left\{x_{n}\right\}\right)$ consists of exactly one point.

Definition 1.4. [[6], Definition 3.1] A sequence $\left\{x_{n}\right\}$ in a CAT(0) space $X$ is said $\Delta$-converges to $x \in X$, if $x$ is the unique asymptotic center of $\left\{u_{n}\right\}$ for every subsequence $\left\{u_{n}\right\}$ of $\left\{x_{n}\right\}$. In this case, one can write $\Delta-\lim _{n} x_{n}=x$ and call $x$ the $\Delta-\lim$ of $\left\{x_{n}\right\}$.

Lemma 1.5. Let $(X, d)$ be a $C A T(0)$ space.

1. [[6], p. 3690] Every bounded sequence in $X$ has a $\Delta$-convergent subsequence.

2. [[7], Proposition 2.1] If $K$ is a closed convex subset of $X$ and if $\left\{x_{n}\right\}$ is a bounded sequence in $K$, then the asymptotic center of $\left\{x_{n}\right\}$ is in $K$.

3. [[4], Lemma 2.8] If $\left\{x_{n}\right\}$ is a bounded sequence in $X$ with $A\left(\left\{x_{n}\right\}\right)=\{x\}$ and $\left\{u_{n}\right\}$ is a subsequence of $\left\{x_{n}\right\}$ with $A\left(\left\{u_{n}\right\}\right)=\{u\}$ and the sequence $\left\{\mathrm{d}\left(x_{n}, u\right)\right\}$ converges, then $x=u$.

\section{Main results}

The following lemma was proved by Dhompongsa and Panyanak in the case of nonexpansive [[4], Lemma 2.10].

Lemma 2.1. Let $K$ be a nonempty closed convex subset of a complete $C A T(0)$ space $X$, and $T: K \rightarrow X$ be a nonself mapping, satisfying Condition $(E)$. Suppose $\left\{x_{n}\right\}$ is a bounded sequence in $K$ such that $\lim _{n} \mathrm{~d}\left(x_{n}, T x_{n}\right)=0$ and $\left\{\mathrm{d}\left(x_{n}, v\right)\right\}$ converges for all $v$ $\in F(T)$. Then

$$
\omega_{w}\left(x_{n}\right) \subset F(T),
$$

where $\omega_{w}\left(x_{n}\right):=\bigcup A\left(\left\{u_{n}\right\}\right)$ and the union is taken over all subsequences $\left\{u_{n}\right\}$ of $\left\{x_{n}\right\}$. Moreover, $\omega_{w}\left(x_{n}\right)$ consists of exactly one point.

Proof. Let $u \in \omega_{w}\left(x_{n}\right)$, then there exists a subsequence $\left\{u_{n}\right\}$ of $\left\{x_{n}\right\}$ such that $A\left(\left\{u_{n}\right\}\right)$ $=\{u\}$. By part (1) and (2) of Lemma 1.5, there exists a subsequence $\left\{v_{n}\right\}$ of $\left\{u_{n}\right\}$ such that $\Delta-\lim _{n} v_{n}=v \in K$. We show $v \in F(T)$. In order to prove this, by Condition $(E)$, one can write

$$
\mathrm{d}\left(x_{n}, T v\right) \leq \mu \mathrm{d}\left(T x_{n}, x_{n}\right)+\mathrm{d}\left(x_{n}, v\right)
$$

for some $\mu \geq 1$. Therefore

$$
\begin{aligned}
\lim \sup _{n} \mathrm{~d}\left(x_{n}, T v\right) & \leq \lim \sup _{n}\left(\mu \mathrm{d}\left(T x_{n}, x_{n}\right)+\mathrm{d}\left(x_{n}, v\right)\right) \\
& =\lim \sup _{n} \mathrm{~d}\left(x_{n}, v\right) .
\end{aligned}
$$


The uniqueness of asymptotic center, implies $v \in K$ and $T(v)=v$. By part (3) Lemma 1.5, $u=v$. Therefore $\omega_{w}\left(x_{n}\right) \subset F(T)$. Let $\left\{u_{n}\right\}$ be a subsequence of $\left\{x_{n}\right\}$ with $A\left(\left\{u_{n}\right\}\right)=$ $\{u\}$ and $A\left(\left\{x_{n}\right\}\right)=\{x\}$. Since $u \in \omega_{w}\left(x_{n}\right) \subset F(T),\left\{\mathrm{d}\left(x_{n}, v\right)\right\}$ converges. By part (3) Lemma $1.5, x=u$. This shows that $\omega_{w}\left(x_{n}\right)$ consists of exactly one point. $\square$

Theorem 2.2. Let $K$ be a nonempty closed convex subset of a complete CAT(0) space $X$, and $T: K \rightarrow X$ be a nonself mapping, satisfying Condition $(E)$ with $x^{\star} \in F(T)=\{x \in$ $K: T x=x\}$. Let $\left\{\alpha_{n}\right\}$ and $\left\{\beta_{n}\right\}$ be sequences in $[\varepsilon, 1-\varepsilon]$ for some $\varepsilon \in(0,1)$. Starting from arbitrary $x_{1} \in K$, define the sequence $\left\{x_{n}\right\}$ by $x_{n+1}=P\left(\left(1-\alpha_{n}\right) x_{n} \oplus \alpha_{n} T P\left[\left(1-\beta_{n}\right)\right.\right.$ $\left.\left.x_{n} \oplus \beta_{n} T x_{n}\right]\right), n \geq 1$. Then $\lim _{n \rightarrow \infty} \mathrm{d}\left(x_{n}, x^{\star}\right)$ exists.

Proof. By part (1) of Lemma 1.3, the nearest point projection $P$ from $X$ onto $K$ is nonexpansive. Then,

$$
\begin{aligned}
\mathrm{d}\left(x_{n+1}, x^{\star}\right) & =\mathrm{d}\left(P\left(\left(1-\alpha_{n}\right) x_{n} \oplus \alpha_{n} T P\left[\left(1-\beta_{n}\right) x_{n} \oplus \beta_{n} T x_{n}\right]\right), P x^{\star}\right) \\
& \leq \mathrm{d}\left(\left(1-\alpha_{n}\right) x_{n} \oplus \alpha_{n} T P\left[\left(1-\beta_{n}\right) x_{n} \oplus \beta_{n} T x_{n}\right], x^{\star}\right) \\
& =\left(1-\alpha_{n}\right) \mathrm{d}\left(x_{n}, x^{\star}\right)+\alpha_{n} \mathrm{~d}\left(T P\left[\left(1-\beta_{n}\right) x_{n} \oplus \beta_{n} T x_{n}\right], x^{\star}\right) .
\end{aligned}
$$

But by Condition $(E)$, for some $\mu \geq 1$, we have

$$
\begin{aligned}
& \left(1-\alpha_{n}\right) \mathrm{d}\left(x_{n}, x^{\star}\right)+\alpha_{n} \mathrm{~d}\left(T P\left[\left(1-\beta_{n}\right) x_{n} \oplus \beta_{n} T x_{n}\right], x^{\star}\right) \\
& \leq\left(1-\alpha_{n}\right) \mathrm{d}\left(x_{n}, x^{\star}\right)+\alpha_{n}\left(\mu \mathrm{d}\left(T x^{\star}, x^{\star}\right)+\mathrm{d}\left(P\left[\left(1-\beta_{n}\right) x_{n} \oplus \beta_{n} T x_{n}\right], x^{\star}\right)\right) \\
& \leq\left(1-\alpha_{n}\right) \mathrm{d}\left(x_{n}, x^{\star}\right)+\alpha_{n}\left[\left(1-\beta_{n}\right) \mathrm{d}\left(x_{n}, x^{\star}\right)+\beta_{n} \mathrm{~d}\left(x_{n}, x^{\star}\right)\right] \\
& =\mathrm{d}\left(x_{n}, x^{\star}\right) .
\end{aligned}
$$

Consequently, $\mathrm{d}\left(x_{n+1}, x^{\star}\right) \leq \mathrm{d}\left(x_{n}, x^{\star}\right)$. Then $\mathrm{d}\left(x_{n}, x^{\star}\right) \leq \mathrm{d}\left(x_{1}, x^{\star}\right)$ for all $n \geq 1$. This implies $\left\{\mathrm{d}\left(x_{n}, x^{\star}\right)\right\}_{n=1}^{\infty}$ is bounded and decreasing. Hence, $\lim _{n \rightarrow \infty} \mathrm{d}\left(x_{n}, x^{\star}\right)$ exists. $\square$

Theorem 2.3. Let $K$ be a nonempty closed convex subset of a complete CAT(0) space $X$, and $T: K \rightarrow X$ be a nonself mapping, satisfying Condition $(E)$ with $F(T) \neq \varnothing$. Let $\left\{\alpha_{n}\right\}$ and $\left\{\beta_{n}\right\}$ be sequences in $[\varepsilon, 1-\varepsilon]$ for some $\varepsilon \in(0,1)$. Starting from arbitrary $x_{1} \in$ $K$, define the sequence $\left\{x_{n}\right\}$ by $x_{n+1}=P\left(\left(1-\alpha_{n}\right) x_{n} \oplus \alpha_{n} T P\left[\left(1-\beta_{n}\right) x_{n} \oplus \beta_{n} T x_{n}\right]\right), n \geq 1$. Then $\lim _{n \rightarrow \infty} d\left(x_{n}, T x_{n}\right)=0$.

Proof. Let $x^{\star} \in F(T)$. By Theorem 2.2, $\lim _{n \rightarrow \infty} \mathrm{d}\left(x_{n}, x^{\star}\right)$ exists. Set

$$
\lim _{n \rightarrow \infty} \mathrm{d}\left(x_{n}, x^{\star}\right)=r .
$$

If $r=0$, by the Condition (E), for some $\mu \geq 1$,

$$
\begin{aligned}
\mathrm{d}\left(x_{n}, T x_{n}\right) & \leq \mathrm{d}\left(x^{\star}, x_{n}\right)+\mathrm{d}\left(x^{\star}, T x_{n}\right) \\
& \leq \mathrm{d}\left(x^{\star}, x_{n}\right)+\mu \mathrm{d}\left(x^{\star}, T x^{\star}\right)+\mathrm{d}\left(x^{\star}, x_{n}\right) .
\end{aligned}
$$

Therefore $\lim _{n \rightarrow \infty} \mathrm{d}\left(x_{n}, T x_{n}\right)=0$.

If $r>0$, set $y_{n}=P\left[\left(1-\beta_{n}\right) x_{n} \oplus \beta_{n} T x_{n}\right]$. By part (4) of Lemma 1.3,

$$
\begin{aligned}
\mathrm{d}\left(y_{n}, x^{\star}\right)^{2} & =\mathrm{d}\left(P\left[\left(1-\beta_{n}\right) x_{n} \oplus \beta_{n} T x_{n}\right], P x^{\star}\right)^{2} \\
& \leq \mathrm{d}\left(\left[\left(1-\beta_{n}\right) x_{n} \oplus \beta_{n} T x_{n}\right], x^{\star}\right)^{2} \\
& \leq\left(1-\beta_{n}\right) \mathrm{d}\left(x_{n}, x^{\star}\right)^{2}+\beta_{n} \mathrm{~d}\left(T x_{n}, x^{\star}\right)^{2}-\beta_{n}\left(1-\beta_{n}\right) \mathrm{d}\left(x_{n}, T x_{n}\right)^{2} \\
& \leq\left(1-\beta_{n}\right) \mathrm{d}\left(x_{n}, x^{\star}\right)^{2}+\beta_{n} \mathrm{~d}\left(T x_{n}, x^{\star}\right)^{2} .
\end{aligned}
$$


Using Condition $(E)$, for some $\mu \geq 1$,

$$
\begin{aligned}
\left(1-\beta_{n}\right) \mathrm{d}\left(x_{n}, x^{\star}\right)^{2} & +\beta_{n} \mathrm{~d}\left(T x_{n}, x^{\star}\right)^{2} \\
& \leq\left(1-\beta_{n}\right) \mathrm{d}\left(x_{n}, x^{\star}\right)^{2}+\beta_{n}\left(\mu \mathrm{d}\left(T x^{\star}, x^{\star}\right)+\mathrm{d}\left(x_{n}, x^{\star}\right)\right)^{2} \\
& =\mathrm{d}\left(x_{n}, x^{\star}\right)^{2} .
\end{aligned}
$$

Therefore by inequities (2.3) and (2.4), one can get

$$
\mathrm{d}\left(y_{n}, x^{\star}\right) \leq \mathrm{d}\left(x_{n}, x^{\star}\right)
$$

Part (4) of Lemma 1.3, shows

$$
\begin{aligned}
\mathrm{d}\left(x_{n+1}, x^{\star}\right)^{2}= & \mathrm{d}\left(P\left[\left(1-\alpha_{n}\right) x_{n} \oplus \alpha_{n} T y_{n}\right], P x^{\star}\right)^{2} \\
\leq & \mathrm{d}\left(\left(1-\alpha_{n}\right) x_{n} \oplus \alpha_{n} T y_{n}, x^{\star}\right)^{2} \\
\leq & \left(1-\alpha_{n}\right) \mathrm{d}\left(x_{n}, x^{\star}\right)^{2}+\alpha_{n} \mathrm{~d}\left(T y_{n}, x^{\star}\right)^{2}-\alpha_{n}\left(1-\alpha_{n}\right) \mathrm{d}\left(x_{n}, T y_{n}\right)^{2} \\
\leq & \left(1-\alpha_{n}\right) \mathrm{d}\left(x_{n}, x^{\star}\right)^{2}+\alpha_{n}\left(\mu \mathrm{d}\left(T x^{\star}, x^{\star}\right)+\mathrm{d}\left(y_{n}, x^{\star}\right)\right)^{2} \\
& -\alpha_{n}\left(1-\alpha_{n}\right) \mathrm{d}\left(x_{n}, T y_{n}\right)^{2} \\
= & \left(1-\alpha_{n}\right) \mathrm{d}\left(x_{n}, x^{\star}\right)^{2}+\alpha_{n} \mathrm{~d}\left(y_{n}, x^{\star}\right)^{2}-\alpha_{n}\left(1-\alpha_{n}\right) \mathrm{d}\left(x_{n}, T y_{n}\right)^{2} \\
\leq & \left(1-\alpha_{n}\right) \mathrm{d}\left(x_{n}, x^{\star}\right)^{2}+\alpha_{n} \mathrm{~d}\left(x_{n}, x^{\star}\right)^{2}-\alpha_{n}\left(1-\alpha_{n}\right) \mathrm{d}\left(x_{n}, T y_{n}\right)^{2} \\
= & \mathrm{d}\left(x_{n}, x^{\star}\right)^{2}-\alpha_{n}\left(1-\alpha_{n}\right) \mathrm{d}\left(x_{n}, T y_{n}\right)^{2} .
\end{aligned}
$$

Therefore

$$
\mathrm{d}\left(x_{n+1}, x^{\star}\right)^{2} \leq \mathrm{d}\left(x_{n}, x^{\star}\right)^{2}-W\left(\alpha_{n}\right) \mathrm{d}\left(x_{n}, T y_{n}\right)^{2},
$$

where $W(\alpha)=\alpha(1-\alpha)$. Since $\alpha \in[\varepsilon, 1-\varepsilon], W\left(\alpha_{n}\right) \geq \varepsilon^{2}$.

Therefore

$$
\varepsilon^{2} \sum_{n=1}^{\infty} \mathrm{d}\left(x_{n}, T y_{n}\right)^{2} \leq \mathrm{d}\left(x_{1}, x^{\star}\right)^{2}<\infty .
$$

This implies $\lim _{n \rightarrow \infty} \mathrm{d}\left(x_{n}, T y_{n}\right)=0$.

By Condition $(E)$, for some $\mu \geq 1$, we have

$$
\begin{aligned}
\mathrm{d}\left(x_{n}, x^{\star}\right) & \leq \mathrm{d}\left(x_{n}, T y_{n}\right)+\mathrm{d}\left(T y_{n}, x^{\star}\right) \\
& \leq \mathrm{d}\left(x_{n}, T y_{n}\right)+\mu \mathrm{d}\left(T x^{\star}, x^{\star}\right)+\mathrm{d}\left(y_{n}, x^{\star}\right) \\
& =\mathrm{d}\left(x_{n}, T y_{n}\right)+\mathrm{d}\left(y_{n}, x^{\star}\right) .
\end{aligned}
$$

Hence

$$
r \leq \liminf _{n \rightarrow \infty} \mathrm{d}\left(y_{n}, x^{\star}\right)
$$

On the other hand, from (2.5),

$$
\limsup _{n \rightarrow \infty} \mathrm{d}\left(y_{n}, x^{\star}\right) \leq r .
$$

This implies

$$
\lim _{n \rightarrow \infty} \mathrm{d}\left(y_{n}, x^{\star}\right)=r .
$$


Thus (2.5) shows

$$
\left.\lim _{n \rightarrow \infty} \mathrm{d}\left(\left(1-\beta_{n}\right) x_{n} \oplus \beta_{n} T x_{n}\right], x^{\star}\right)=r .
$$

Since $T$ satisfies Condition $(E)$, we have

$$
\begin{aligned}
\mathrm{d}\left(T x_{n}, x^{\star}\right) & \leq \mu \mathrm{d}\left(T x^{\star}, x^{\star}\right)+\mathrm{d}\left(x_{n}, x^{\star}\right) \\
& =\mathrm{d}\left(x_{n}, x^{\star}\right)
\end{aligned}
$$

Thus

$$
\limsup _{n \rightarrow \infty} \mathrm{d}\left(T x_{n}, x^{\star}\right) \leq r .
$$

Now, by [[1], Lemma 2.9], $\lim _{n \rightarrow \infty} \mathrm{d}\left(x_{n}, T x_{n}\right)=0$. $\square$

Theorem 2.4. Let $K$ be a nonempty closed convex subset of a complete $C A T(0)$ space $X$, and $T: K \rightarrow X$ be a nonself mapping, satisfying Condition $(E)$ with $F(T) \neq \varnothing$. Assume $\left\{\alpha_{n}\right\}$ and $\left\{\beta_{n}\right\}$ are sequences in $[\varepsilon, 1-\varepsilon]$ for some $\varepsilon \in(0,1)$. Starting from arbitrary $x_{1} \in K$, define the sequence $\left\{x_{n}\right\}$ by $x_{n+1}=P\left(\left(1-\alpha_{n}\right) x_{n} \oplus \alpha_{n} T P\left[\left(1-\beta_{n}\right) x_{n} \oplus\right.\right.$ $\left.\left.\beta_{n} T x_{n}\right]\right), n \geq 1$. Then $\left\{x_{n}\right\}$ is $\Delta$-convergent to some point $x^{\star}$ in $F(T)$.

Proof. By Theorem 2.3, $\lim _{n \rightarrow \infty} \mathrm{d}\left(x_{n}, T x_{n}\right)=0$. The proof of Theorem 2.2 shows $\{\mathrm{d}$ $\left.\left(x_{n}, v\right)\right\}$ is bounded and decreasing for each $v \in F(T)$, and so it is convergent. By Lemma 2.1, $\omega_{w}\left(x_{n}\right)$ consists exactly one point which is a fixed point of $T$. Consequently, the sequence $\left\{x_{n}\right\}$ is $\Delta$-convergent to some point $x^{\star}$ in $F(T)$. $\square$

The following definition is recalled from [8].

Definition 2.5. A mapping $T: K \rightarrow X$ is said to satisfy Condition $I$, if there exists a nondecreasing function $f:[0, \infty) \rightarrow[0, \infty)$ with $f(0)=0$ and $f(r)>0$ for all $r>0$ such that

$$
\mathrm{d}(x, T x) \geq f(\mathrm{~d}(x, F(T)))
$$

where $x \in K$.

With respect to the above definition, we have the following theorem [[1], Theorem 3.4].

Theorem 2.6. Let $K$ be a nonempty closed convex subset of a complete $C A T(0)$ space $X$, and $T: K \rightarrow X$ be a nonself mapping, satisfying condition $(E)$ with $F(T) \neq \varnothing$. Assume $\left\{\alpha_{n}\right\}$ and $\left\{\beta_{n}\right\}$ are sequences in $[\varepsilon, 1-\varepsilon]$ for some $\varepsilon \in(0,1)$. Starting from arbitrary $x_{1} \in$ $K$, define the sequence $\left\{x_{n}\right\}$ by $x_{n+1}=P\left(\left(1-\alpha_{n}\right) x_{n} \oplus \alpha_{n} T P\left[\left(1-\beta_{n}\right) x_{n} \oplus \beta_{n} T x_{n}\right]\right), n \geq 1$. If $T$ satisfies condition I, then $\left\{x_{n}\right\}$ converges strongly to a fixed point of $T$.

We state another strong convergence theorem [[1], Theorem 3.5] as follows:

Theorem 2.7. Let $K$ be a nonempty compact convex subset of a complete $C A T(0)$ space $X$, and $T: K \rightarrow X$ be a nonself mapping, satisfying condition $(E)$ with $F(T) \neq \varnothing$. Assume $\left\{\alpha_{n}\right\}$ and $\left\{\beta_{n}\right\}$ are sequences in $[\varepsilon, 1-\varepsilon]$ for some $\varepsilon \in(0,1)$. Starting from arbitrary $x_{1} \in K$, define the sequence $\left\{x_{n}\right\}$ by $x_{n+1}=P\left(\left(1-\alpha_{n}\right) x_{n} \oplus \alpha_{n} T P\left[\left(1-\beta_{n}\right) x_{n} \oplus\right.\right.$ $\left.\left.\beta_{n} T x_{n}\right]\right), n \geq 1$. Then, $\left\{x_{n}\right\}$ converges strongly to a fixed point of $T$.

Another result in [1] is to obtain the $\Delta$-convergence of a defined sequence, to a common fixed point of two nonexpansive self-mappings. According to the present setting, we can state the following result.

Theorem 2.8. Let $K$ be a nonempty closed convex subset of a complete $C A T(0)$ space $X$, and $S, T: K \rightarrow X$ be two nonself mappings, satisfying Condition $(E)$ with $F(S) \cap F(T)$ 
$\neq \varnothing$. Assume $\left\{\alpha_{n}\right\}$ and $\left\{\beta_{n}\right\}$ are sequences in $[\varepsilon, 1-\varepsilon]$ for some $\varepsilon \in(0,1)$. Starting from arbitrary $x_{1} \in K$, define the sequence $\left\{x_{n}\right\}$ by $x_{n+1}=\left(1-\alpha_{n}\right) x_{n} \oplus \alpha_{n} S\left[\left(1-\beta_{n}\right) x_{n} \oplus\right.$ $\left.\beta_{n} T x_{n}\right], n \geq 1$. Then $\left\{x_{n}\right\}$ is $\Delta$-convergent to a common fixed point of $S$ and $T$.

\section{Authors' contributions}

The authors have contributed in obtaining the new results presented in this article. All authors read and approved the final manuscript.

\section{Competing interests}

The authors declare that they have no competing interests.

Received: 24 May 2011 Accepted: 13 October 2011 Published: 13 October 2011

\section{References}

1. Laowang, W, Panyanak, B: Approximating fixed points of nonexpansive nonself mappings in CAT(0) spaces. Fixed Point Theory Appl. 367274, 11 (2010)

2. Garcia-Falset, J, Liorens-Fuster, E, Suzuki, T: Fixed point theory for a class of generalized nonexpansive mapping. J Math Anal Appl. 375, 185-195 (2011). doi:10.1016/j.jmaa.2010.08.069

3. Bridson, M, Haefliger, A: Metric Spaces of Non-Positive Curvature, Fundamental Principles of Mathematical Sciences. Springer, Berlin319 (1999)

4. Dhompongsa, S, Panyanak, B: On $\Delta$-convergence theorems in CAT(0) spaces. Comput Math Appl. 56, $2572-2579$ (2008) doi:10.1016/j.camwa.2008.05.036

5. Dhompongsa, S, Kirk, WA, Sims, B: Fixed point of uniformly lipschitzian mappings. Nonlinear Anal. 65, 762-772 (2006). doi:10.1016/j.na.2005.09.044

6. Kirk, W, Panyanak, B: A concept of convergence in geodesic spaces. Nonlinear Anal. 68, 3689-3696 (2008). doi:10.1016/j. na.2007.04.011

7. Dhompongsa, S, Kirk, WA, Panyanak, B: Nonexpansive set-valued mappings in metric and Banach spaces. J Nonlinear Convex Anal. 8, 35-45 (2007)

8. Senter, HF, Dotson, WG: Approximating fixed points of nonexpansive mappings. Proc Am Math Soc. 44, 375-380 (1974). doi:10.1090/S0002-9939-1974-0346608-8

doi:10.1186/1687-1812-2011-65

Cite this article as: Razani and Shabani: Approximating fixed points for nonself mappings in CAT(0) spaces. Fixed Point Theory and Applications 2011 2011:65.

\section{Submit your manuscript to a SpringerOpen ${ }^{\circ}$} journal and benefit from:

- Convenient online submission

Rigorous peer review

- Immediate publication on acceptance

- Open access: articles freely available online

- High visibility within the field

- Retaining the copyright to your article

Submit your next manuscript at $\mathbf{s p r i n g e r o p e n . c o m ~}$ 